\title{
Twenty years of geomagnetic field observations at Mario Zucchelli Station (Antarctica)
}

\author{
Lili Cafarella, Stefania Lepidi, Antonio Meloni and Lucia Santarelli \\ Istituto Nazionale di Geofisica e Vulcanologia, Roma, Italy
}

\begin{abstract}
During the 1986-87 austral summer a geomagnetic observatory was installed at Terra Nova Bay. During the first years both geomagnetic field time variation monitoring and absolute measurements were carried out only during summer. Since 1991 variometer measurements are automatically performed throughout the year, while absolute measurements are still performed only during summer. In spite of this, interesting observations were obtained during the life (quite long for Antarctica) of the geomagnetic observatory. In particular, this paper briefly presents some of the most important results: studies on secular variation, daily variation (and its dependence from solar cycle and seasons) and geomagnetic higher frequency variations, such as geomagnetic pulsations.
\end{abstract}

Key words geomagnetic observatory - geomagnetic field variations - Antarctica

\section{Introduction}

The magnetic field of internal origin is a manifestation of a magnetohydrodynamic dynamo acting in the interior of the Earth. This field represents over 97 per cent of what is observed at the Earth's surface. In addition to sources in the Earth's core, the geomagnetic field is produced by sources in the lithosphere and, regards contributions external to the Earth, from electric currents flowing in the ionosphere, magnetosphere, as well as from the coupling of these currents and the currents flowing between the two Earth's hemispheres.

A first order classification of the different

Mailing address: Dr. Lili Cafarella, Istituto Nazionale di Geofisica e Vulcanologia (INGV), Via di Vigna Murata 605, 00143 Roma, Italy: e-mail: lili.cafarella@ingv.it studies on the Earth's magnetic field time variations can be made on the rough basis of internal and external Earth studies respectively. Even if it is not possible to establish a precise boundary between the two groups, by applying spherical harmonics analysis to the geomagnetic field time variations, it has been found that the variations on time scales shorter than 1-5 years are of external origin while those that take place on longer time scales, commonly referred to as secular variation, are of internal origin (see for example Chapman and Bartels, 1940; Parkinson, 1983; Backus et al., 1996; Merrill et al., 1996; Mandea and Purucker, 2005; Lanza and Meloni, 2006; for space physics aspects Hargreaves, 1992; Kivelson and Russell, 1996).

In Italy, the Istituto Nazionale di Geofisica e Vulcanologia (INGV) is responsible for systematic magnetic observations made by means of observatories and repeat stations. At present two regularly working geomagnetic observatories cover central and northern Italy: L'Aquila (the main Italian observatory since 1958) and Castello Tesino (since 1964). A new observatory is being installed in the southern Mediterranean (near Sicily) at Lampedusa Island. Once 
this installation is successfully completed, the three observatories will be able to provide a full coverage of the whole Italian latitudinal extension (Meloni et al., 2007a).

As regards polar observatories, Italy is involved in the management of two geomagnetic observatories at Mario Zucchelli station (TNB) and Concordia Station (on the high East Antarctic craton at DomeC) respectively. The first was installed at Terra Nova Bay (Ross Sea) during 1986/1987 austral summer by the PNRA (Italian program for scientific research in Antarctica; Palangio et al, 1996); in February 2005 the permanent scientific station Concordia opened and, from 2004-2005 summer expedition, also a geomagnetic observatory, common- ly operated with French colleagues, started its operation (Schott et al., 2005).

This paper briefly describes some interesting observations made on the long TNB dataset. In particular some studies on secular variation, daily variation (and its dependence from solar cycle and seasons) and geomagnetic higher frequency variations, such as geomagnetic pulsations, are here briefly summarized.

\subsection{The geomagnetic observatory}

The Italian program for scientific research in Antarctica installed, during 1986/1987 austral summer, a geomagnetic observatory at Ter-

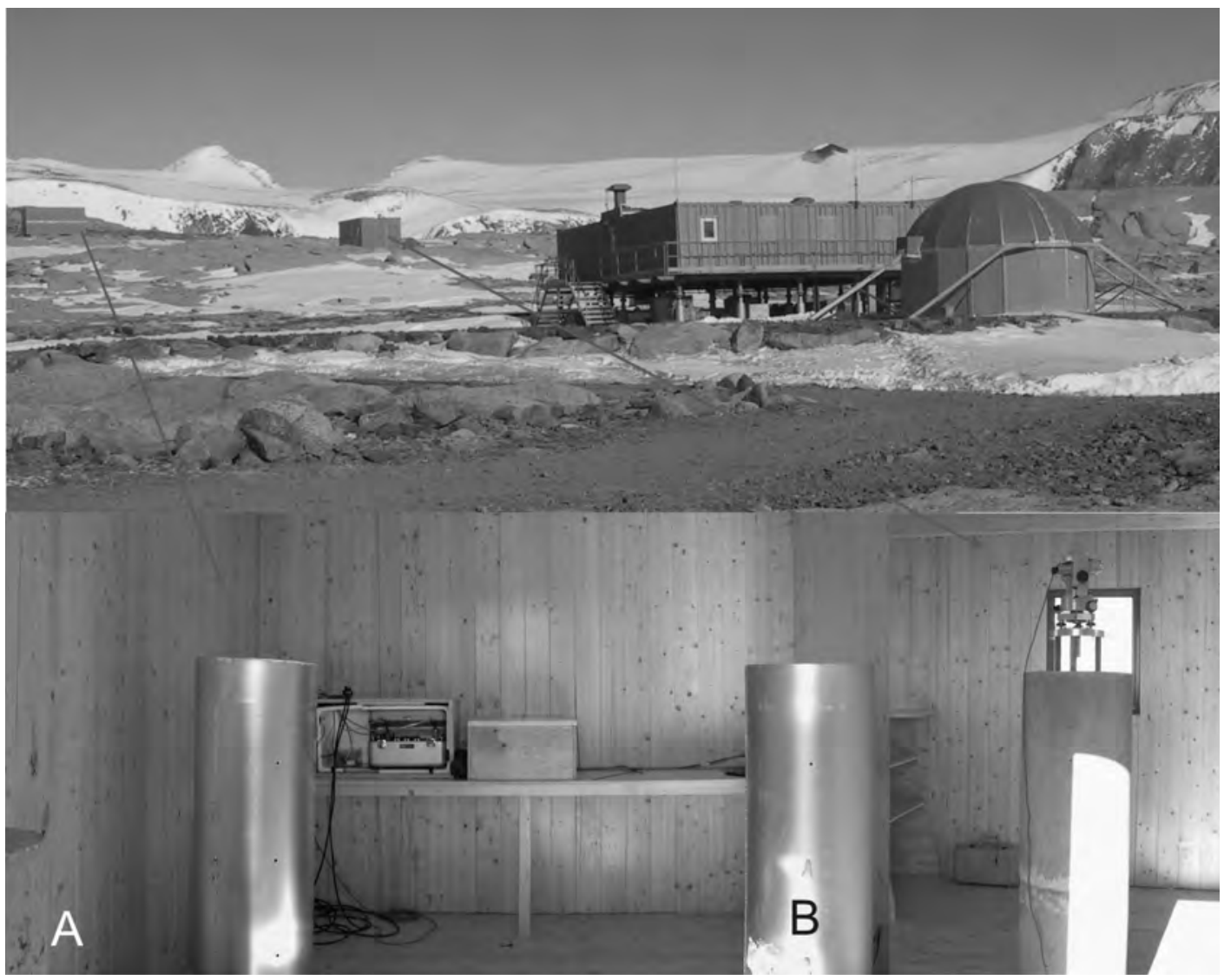

Fig. 1a,b. Geomagnetic observatory at Mario Zucchelli Station: a) variometer shelter; b) absolute measurement shelter. 
ra Nova Bay (observatory IAGA code TNB; geographic coordinates: $74.68^{\circ} \mathrm{S}, 164.12^{\circ} \mathrm{E}$; corrected geomagnetic latitude: $80.0^{\circ} \mathrm{S}$ ) at the Antarctic Italian base Mario Zucchelli Station (formerly Terra Nova Bay). Variations of the Earth's magnetic field are recorded by means of three-axis fluxgate magnetometers (Meloni et al., 1994; Palangio et al., 1996) oriented along three perpendicular directions according to the magnetic reference system: the horizontal magnetic field intensity H-component (along the local magnetic meridian, South-North), the orthogonal-component D in the horizontal plane (West-East; it is on average null, and is due to rapid time variations; D is here an intensive element, expressed consequently in $\mathrm{nT}$; note that in general declination $\mathrm{D}$ is an angular element) and the vertical intensity Z-component (consequently positive increasing inward). The intensity of the geomagnetic field $\mathbf{F}$ is measured by an overhauser magnetometer. At the beginning, measurements were carried out only during TNB opening period, in local summer, while since 1991 an automatic acquisition system, operating throughout the year, was put into operation. In the first ten years, the data sampling rate has varied from 15-30 s (during the station opening period) to 4 min (automatic acquisition during winter period) while since 1996, 1-min data are routinely produced in INTERMAGNET standard. Starting from 2001, the sampling rate is $1 \mathrm{~s}$ and the original $1 \mathrm{~s}$ measurements are stored, and also filtered and averaged to produce $1 \mathrm{~min}$ data. Absolute measurements of the angular elements D and I, fundamental to ensure that the drift of any kind in the recording instruments is corrected, are performed regularly during the Italian Base opening period (unfortunately only during austral summer). Figure 1 a picture of the instrument installation in the sensor shelter is reported. In the figure the insulated variometer sensors and the electronic parts are clearly visible.

\section{Internal Earth studies: secular variation}

For the Earth's interior, one of the most important aims of a magnetic observatory is to supply information for defining global model of the Earth's geomagnetic field and its longterm variation. The International Geomagnetic Reference Field (IGRF) is the first and most well known global model adopted for the first time in 1968. It represents the main magnetic field (of core origin) without external sources and is based on data from satellites, observatories and surveys around the world. Other models for the main field, for example GUFM1 and CALS7K, are based on records from maritime voyages, marine and continental surveys, geomagnetic observatories and satellites the former, and on archeo and paleomagnetic data the latter (intensity and direction).

Global models can be used to represent the main field including other magnetic contributions. The most used are CHAOS, which represents the main plus the crustal field, based on high precision satellite data (Ørsted, CHAMP, SAC-C); CM4, the main field plus the contribution of lithosperic, ionospheric and magnetospheric fields, based on satellite (Magsat, POGO, Ørsted, CHAMP, SAC-C) and observatory data.

The longterm variation of the geomagnetic field elements is called secular variation. Many studies have shown that secular variation is a feature of the main geomagnetic field and that the amount of change varies smoothly with latitude (Parkinson, 1983). The analysis of secular variation as recorded in Antarctic observatories in recent years, shows a rapid decrease in the total magnetic field (e.g. Rajaram et al., 2002). Some investigators (e.g. De Santis et al., 2004) have speculated that this rapid decrease would be of global relevance implying the development of a dipole reversal as has happened several times in the Earth's history, but others have denied this possibility (Gubbins et al., 2006) on the basis of available information.

Both observatory data and CM4 quiet time magnetic field model, were used to improve our knowledge of geomagnetic jerks (abrupt changes of secular variation) in Antarctica, as reported by Meloni et al. (2006, 2007b). Figure 2 shows secular acceleration maps relative to the Y component (along the geographic WestEast direction) over the Antarctic continent obtained using synthetic data given by the CM4 model (from Meloni et al., 2007b). The time se- 

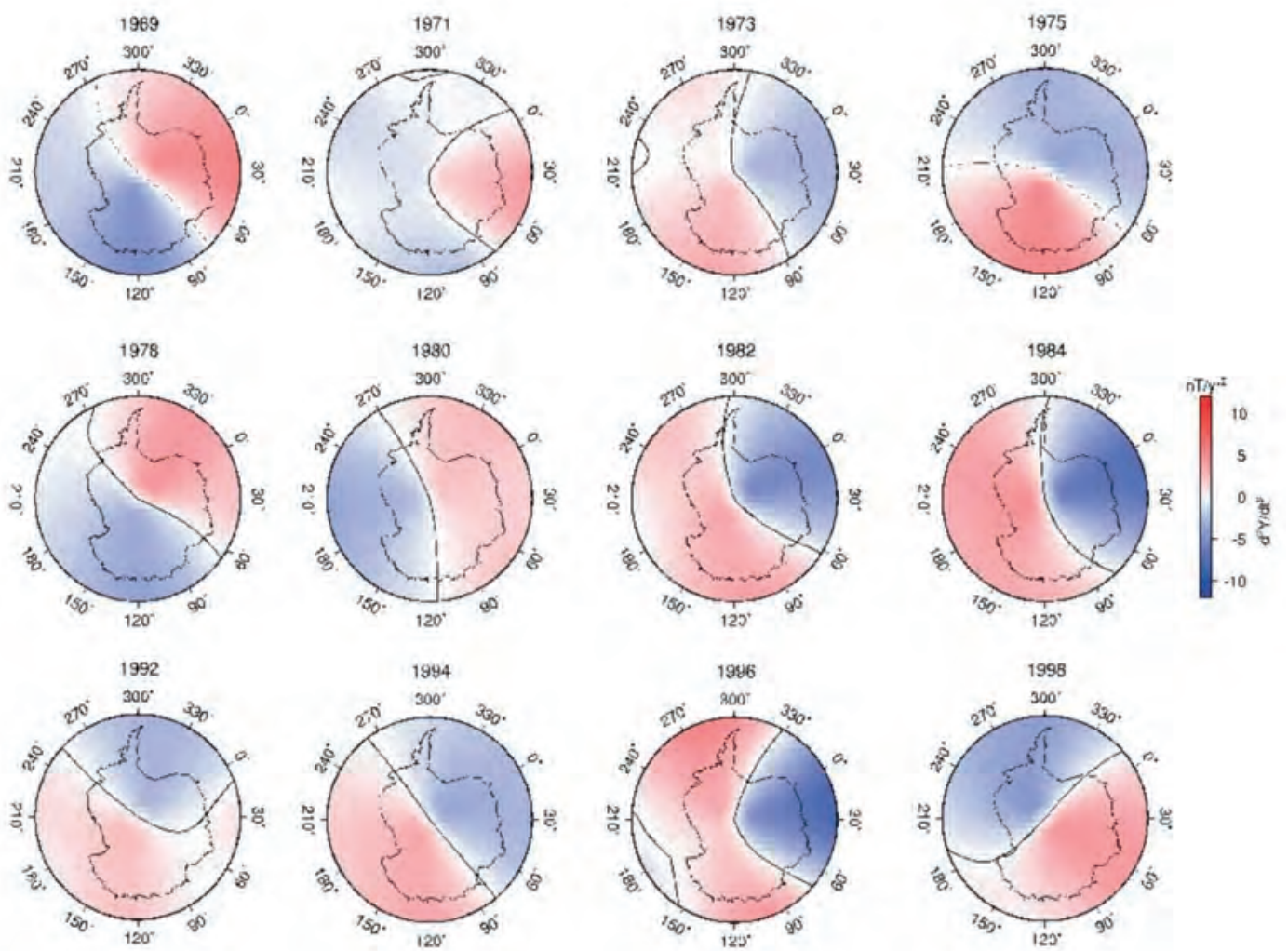

Fig. 2. Secular acceleration maps relative to the $Y$ component over the Antarctic continent obtained using synthetic data given by the CM4 model. The solid line corresponds to the zero separating the zone characterized by negative (blue) and positive (red) values of secular acceleration.

quence of the maps in the three rows in fig. 2 are chosen such as to investigate the secular variation changes around the 1969, 1978 and 1991 jerks (Alexandrescu et al., 1996; De Michelis et al., 2000; Blohxam et al., 2002; Chambodut and Mandea, 2005). The solid line corresponds to the zero separating the zone characterized by negative (blue) and positive (red) values of secular acceleration. The abrupt change in color (blue-red, red-blue) of the secular acceleration maps suggests that the 1969 jerk actually occurred in the Antarctic region around 1972, the 1978 jerk around 1981, and the 1991 event around 1997.

Spherical harmonic analyses of the main field, as well as in general magnetic models, made for different epochs, are used to make world charts of secular variation (isoporic charts). Antarctica is characterized by one of the isoporic foci (areas of maximum temporal variation of the main field elements) so the monitoring of the absolute level of all magnetic field elements here is particularly important.

Unfortunately TNB cannot be fully included among the geomagnetic observatories that can contribute regularly to the internal earth studies because its dataset includes baselines for only two or three months a year, depending on the opening period of Mario Zucchelli station. In spite of this some consideration can be made. Figure 3 shows field time evolution plots (yearly data points, obtained from only summer expeditions data) and IGRF corresponding yearly values for $\mathrm{H}, \mathrm{D}, \mathrm{Z}$ and $\mathrm{F}$ elements. In the 

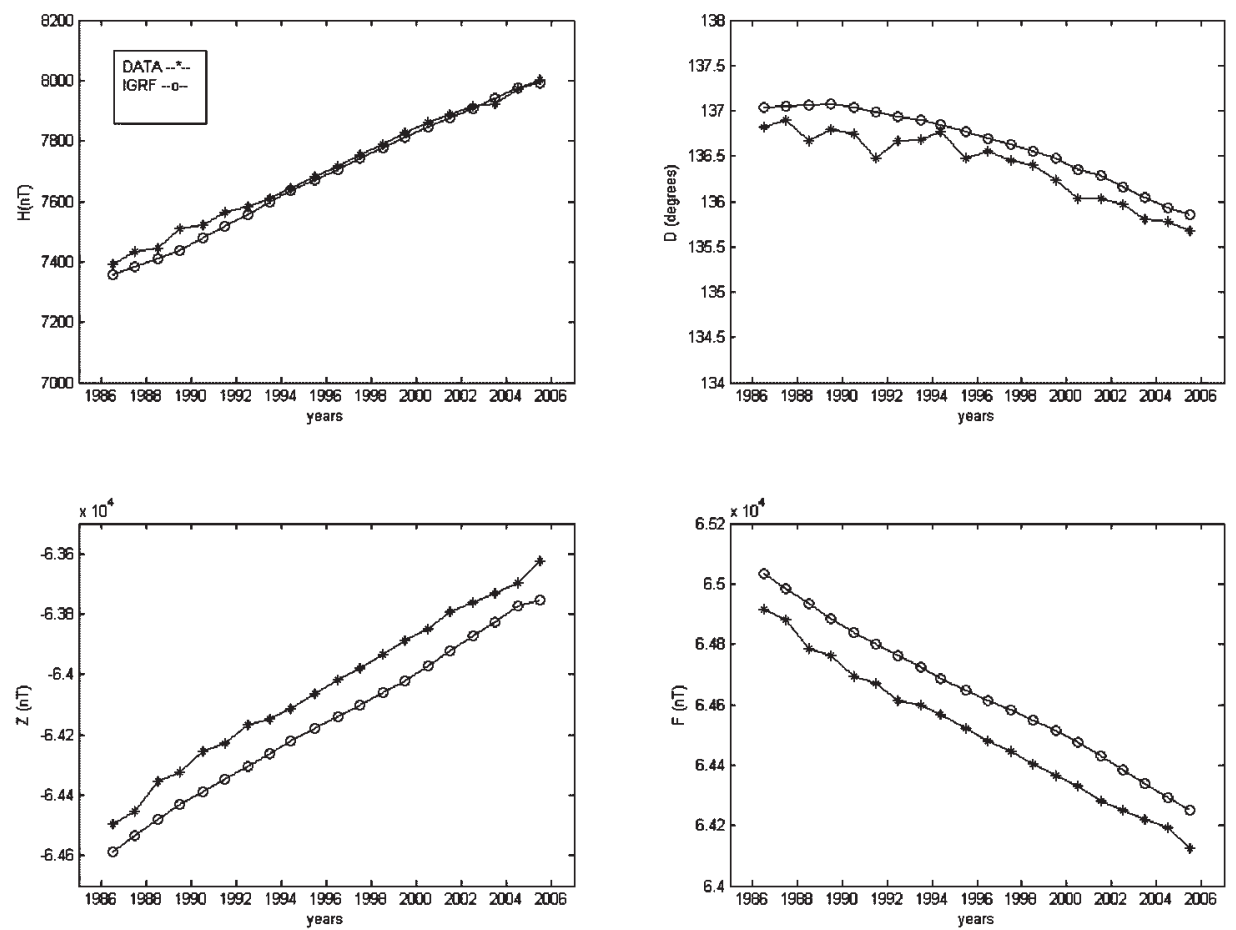

Fig. 3. Long-term time evolution of the $\mathrm{H}, \mathrm{D}, \mathrm{Z}$ and $\mathrm{F}$ elements at Mario Zucchelli Station, shown by their summer mean values (stars) and corresponding IGRF values (circles) (1986-2006).

TNB total field F plot, an almost steady decrease of about 50 nT/year is evident according to the results proposed by Rajaram et al. (2002) and described above while other elements show a regular steady time variation typical of this part of the world.

\section{External Earth studies}

In a static model of the magnetosphere, the Earth's magnetic field lines closed within the lower latitude magnetosphere separate from those at higher latitude that are swept back on the tailward side and can be connected to the Interplanetary Magnetic Field (IMF). The region which separates sunward, closed field lines from tailward, open ones, i.e. the polar cusp, is a funnel which allows a direct entry of solar wind (SW) particles in the magnetos- phere. The connection of the polar regions to the polar cusp and to the boundary between the magnetosphere and the SW (magnetopause) is one of the causes of some peculiar magnetospheric dynamic phenomena of external origin. Moreover, in the whole auroral zone field aligned currents flow into and away from the ionosphere, giving rise to particular geomagnetic variations. In this sense, knowledge and understanding of high latitude phenomena lead to a more complete view of the interactions that exist among various components of the magnetosphere-SW system (McPherron, 2008).

TNB geomagnetic observatory is located at corrected geomagnetic latitude $80.0^{\circ} \mathrm{S}$; the relationship of universal to local time is LT $=\mathrm{UT}+$ 13 and to magnetic local time is MLT $=\mathrm{UT}-8$. The observatory is generally located at the footprint of magnetospheric field lines open in the geomagnetic tail, i.e. in the polar cap. Since the 


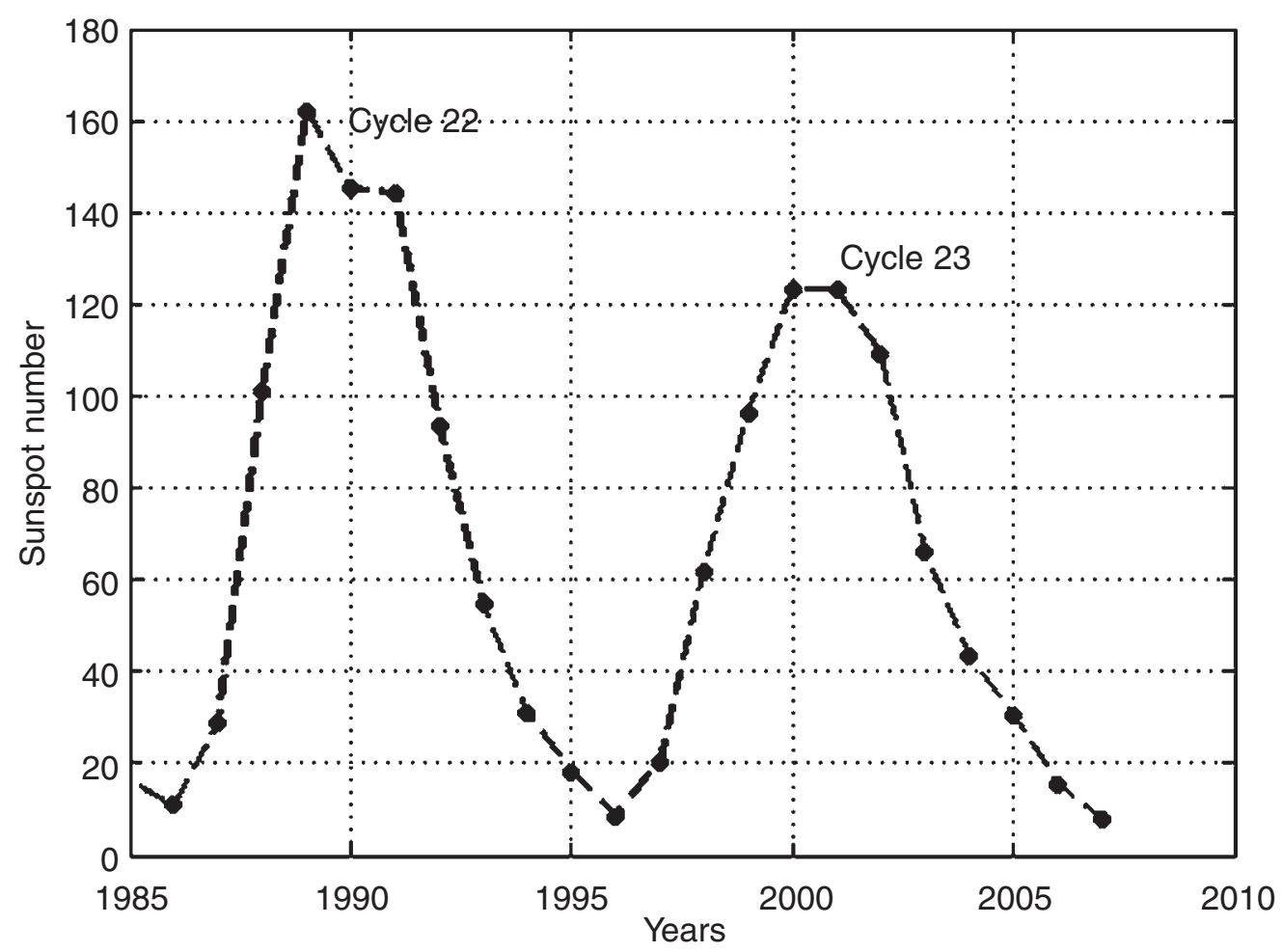

Fig. 4. Yearly average Sunspot number in the time interval 1985-2007.

auroral oval location and extent depend on interplanetary parameters (Zhou et al., 2000), in particular conditions around local geomagnetic noon the station could be situated in the polar cusp, approaching closed field lines. In this sense, the position of the observatory allows many phenomena characteristic of the polar areas, very peculiar zones of the magnetosphere to be studied.

Before summarizing some magnetic field variation observations made at TNB, a brief description of the two solar cycles over which the analyzed data span is useful: Solar cycles 22 and 23 (see fig. 4). Solar cycle 22 started at the end of 1986 and reached its maximum in 1991. It lasted unusually only 9.8 years, but it showed some extraordinary intervals of activity (for example in June 1991). Solar cycle 23 started in May 1996 with the yearly sunspot number at 8.0 and reached its maximum in April 2000 at
120.8; it had a second, smaller peak at 115.5 in November 2001. Now, in 2008 we are just in a minimum (reached in January 2008). Solar cycle 23 has shown on the overall a modest activity in comparison with the two previous solar cycles 21 and 22.

\subsection{Daily variation}

A periodic change in magnetic declination with 24-h period was discovered by George Graham in 1724. Since then, many studies have investigated the daily variation, which can be observed on all geomagnetic field elements and, although with different characteristics, all over the Earth's surface. Today it is well known that daily variation $\left(\mathrm{S}_{\mathrm{q}}\right)$, during quiet solar conditions, is principally generated by two electric current vortices that flow in the dayside upper 


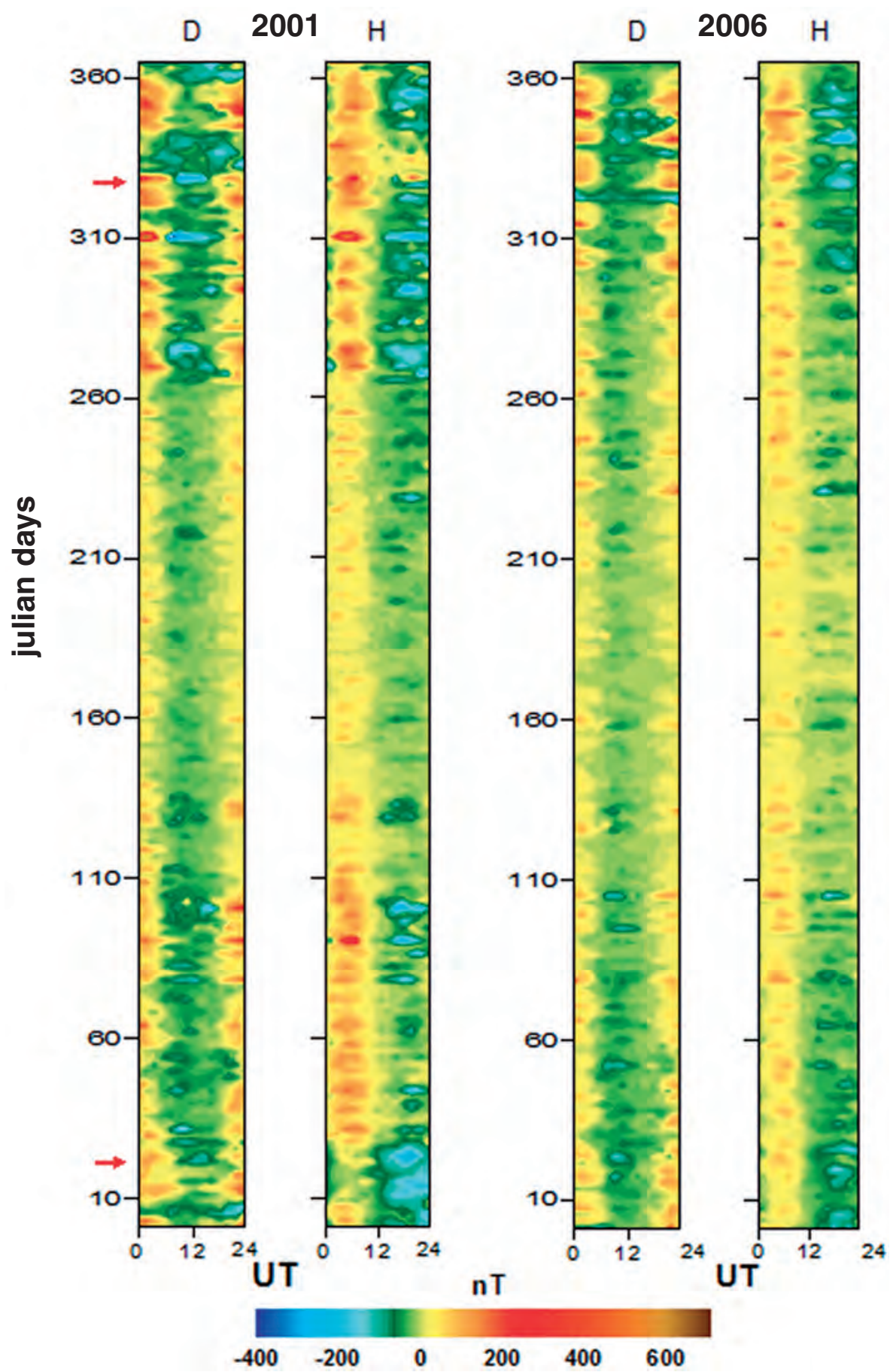

Fig. 5. Dynamic maps of diurnal variation for $D$ and $H$ components for 2001 and 2006 years. 
atmosphere, peaking at altitudes around $110 \mathrm{~km}$ above the Earth's surface, whose focus is located around the noon meridian, at about $30^{\circ}$ geographic latitude in each hemisphere. The daily variation of the geomagnetic field in the polar cap regions is due to a polarward extension of this mid latitude current vortices (called $\mathrm{S}_{\mathrm{q}}{ }^{0}$ ) and to an additional equivalent electric current system contribution typical of polar regions related to the magnetospheric conditions, called $\mathrm{S}_{\mathrm{q}}{ }^{\mathrm{p}}$ (Matsushita and $\mathrm{Xu}, 1982$ ). In particular, this $\mathrm{S}_{\mathrm{q}}{ }^{\mathrm{p}}$ electric current system is the primary source during winter, when the southern polar cap is not directly exposed to the Sun (Akasofu et al., 1983; Brekke, 1997).

Daily variation as observed at Italian polar geomagnetic observatories, was described in previous works by Cafarella et al. (1998), Lepidi et al. (2003), Cafarella et al. (2007a) and Santarelli et al. (2007a). In one of them the study of daily variation, as observed at TNB observatory through fourteen years of data, showed a pronounced seasonal effect on the amplitude of the signal but not on its pattern. An analysis of the same phenomenon at Dome $\mathrm{C}$ (corrected geomagnetic coordinates $88.9^{\circ} \mathrm{S}$ ) was also performed and a pronounced day-today variability of the amplitude was found and explained in terms of the global magnetospheric activity level. This paragraph will show the main daily variation characteristics as observed at TNB during the last two solar cycles.

A comparison of daily variation pattern at TNB for a year of high (2001) and one of low (2006) magnetic activity is reported in fig. 5. The dynamic maps report the variation of the hourly $\mathrm{H}$ and $\mathrm{D}$ values with respect to the average level as a function of julian days and UT. Some considerations can be made immediately looking at the figure. Comparing the same component, diurnal variation trend is similar in both years independently from magnetic activity: indeed D is minimum around 12 UT and maximum at UT midnight while $\mathrm{H}$ is maximum before $12 \mathrm{UT}$ and minimum in the UT afternoon. A clear seasonal dependence of the daily variation amplitude range emerges through each year with a reduction during local winter. As expected, on average the signal amplitude for both elements is higher in 2001 than 2006.
Moreover in the year of minimum solar activity the trend is very stable, while some peculiar structures are evident in the year of maximum activity: for example at the beginning and at the end of 2001 (around Julian days 20 and 330 indicated by red arrows in the figure) the diurnal variation shows an enhanced UT dependence, especially for $\mathrm{H}$.

Figure 6 shows another kind of representation of diurnal variation, i.e. magnetic field hodograms in the horizontal plane, in which every point shows $\mathrm{H}$ and $\mathrm{D}$ values as reported on vertical and horizontal axis respectively. The hodogram representation of the daily variation allows to visualize simultaneously several years and to compare quickly the effects of different solar cycles on geomagnetic field variations. Each hodogram, represented with a different color in fig. 6 , corresponds to one year of solar cycles 22 and 23 . The $24 \mathrm{H}$ and D values in each plot are the median values (from hourly data, after removing the average level) computed over summer season (Jan-Feb-Nov-Dec; Lloyd, 1861), separately for the 24 daily hours. In this representation the 24 values represent the dynamic through the day of the projection of the total field $\mathrm{F}$ on the horizontal plane. In the plots each curve is covered in counterclockwise direction. From the figure the daily variation dependence on solar activity clearly emerges: for both solar cycles the largest and smallest excursions are found in the years corresponding to maximum and minimum sunspot numbers, respectively. Moreover the largest excursions are observed in solar cycle 22, and this is a direct consequence of the fact that solar cycle 23 was not particularly active.

\subsection{Magnetic pulsations}

Magnetic pulsations are geomagnetic field rapid time variations of external origin. Their period ranges from less than 1 second to $10 \mathrm{~min}$ utes, and the amplitude from tenths to hundred $\mathrm{nT}$, generally increasing for increasing period and geomagnetic latitude, maximizing in the auroral zone. The availability of long series of data, gave rise to several studies characterizing the low frequency pulsation activity at TNB. The re- 

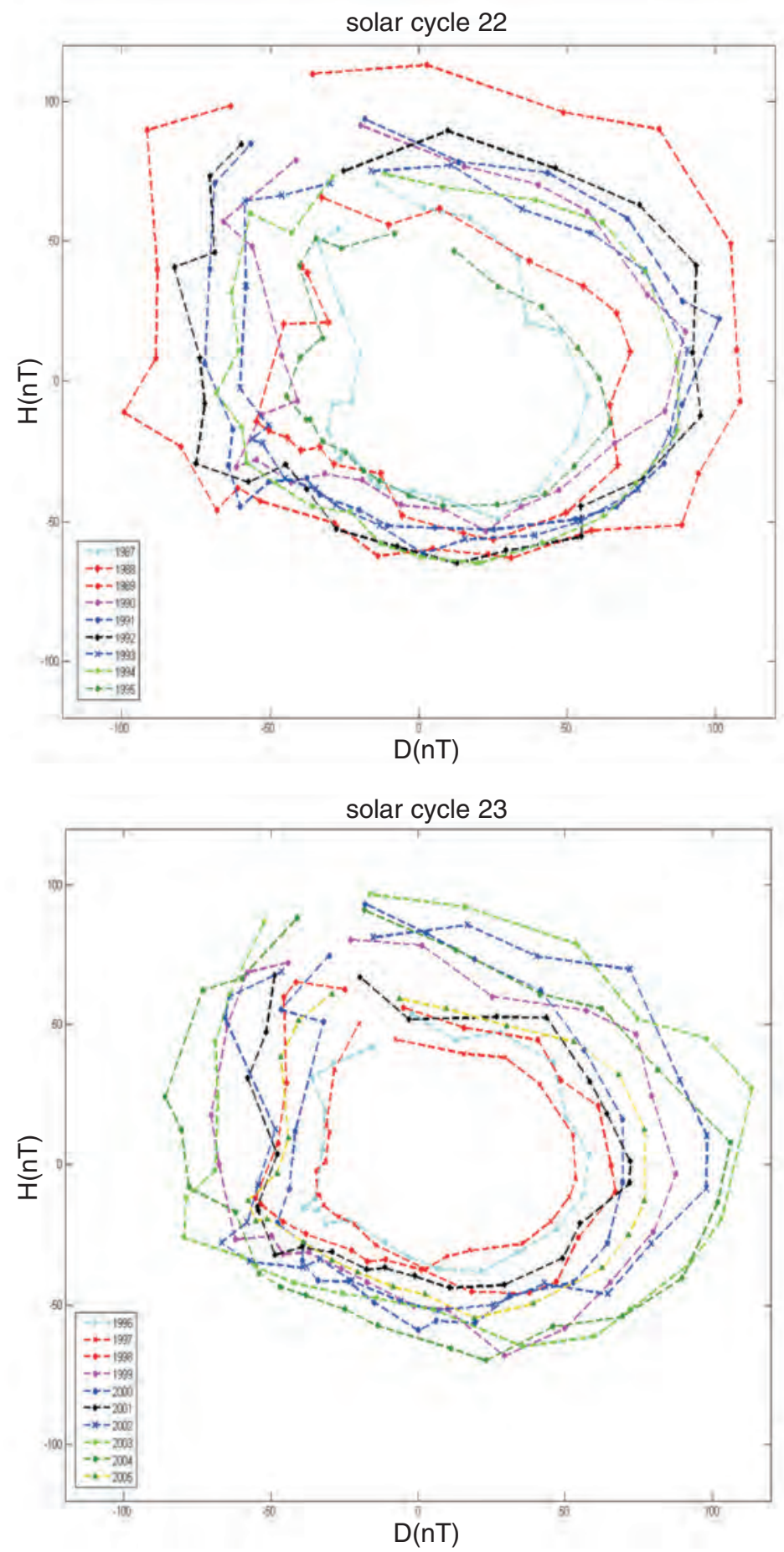

Fig. 6. Magnetic field hodograms for solar cycle 22 and solar cycle 23. 
search activity was mainly devoted to the lowest frequency pulsations (known as Pc5 pulsations, with $\mathrm{f}=2-7 \mathrm{mHz}$ ), with some studies also in the mid frequency range (Pc3-Pc4, with $\mathrm{f}=7-100$ $\mathrm{mHz}$ ); see the reviews by Villante et al. (2000) and Cafarella et al. (2007b).

The generation mechanisms for Pc3-Pc5 pulsations are basically related to instabilities along the flanks of the magnetopause due to the SW flow (Kelvin-Helmholtz Instability; Atkinson and Watanabe, 1966), waves generated upstream of the Earth's bow shock by solar wind ions reflected back (Greenstadt et al., 1981), and to local phenomena in the auroral oval region (Engebretson et al., 1986). The key role of the cusp region in the generation of low frequency pulsations clearly emerges from the result that the average pulsation power at TNB maximizes around local geomagnetic noon, when the station approaches the cusp and local field lines are at minimum distance from the magnetopause (Lepidi et al., 1996). This feature clearly emerges also from fig. 7 (adapted from Santarelli et al., 2007b), where we show a pulsation event recorded at TNB (red line) and at another Antarctic station, Scott Base (SBA, blue line), which has a longitudinal displacement of about 1 hour in magnetic local time with respect to TNB (table I). At both stations there is a sustained wave activity (upper panel); from the $1-5 \mathrm{mHz}$ filtered data (lower panel) it is evident that the wave activity at the two stations is very similar, but the amplitude is larger at SBA around 17-18 UT and at TNB around 21-22 UT, i.e. it is larger at the station which is closer to its local geomagnetic noon, indicating an increasing amplitude approaching the cusp region. It is also evident that around 17 UT SBA is leading (sees the signal in advance) with respect to TNB, while around $21 \mathrm{UT}$ TNB is leading with respect to SBA; this feature clearly indicates that the waves propagate away from the noon region, i.e. they propagate in the antisunward direction, as expected for a generation mechanism such as the Kelvin-Helmholtz instability on the magnetopause.

An additional generation mechanism for low frequency pulsations is related to interplanetary shocks impacting the magnetopause. Such an impact can trigger cavity/waveguide modes of the entire magnetospheric cavity, localized between an outer boundary, for instance the magnetopause, and an inner turning point (Kivelson and Southwood, 1985). The peculiar feature of these modes is that they have a global character within the magnetosphere and are characterized by a set of discrete, stable frequencies. These cavity modes have been observed at auroral and low latitude, and they have also been observed deep in the polar cap, i.e. at the footprint of

Table I. Stations, geographic coordinates, IGRF2003 corrected geomagnetic coordinates and time in UT of the magnetic local noon for the stations used for the analysis in figs. 7 and 8.

\begin{tabular}{cccc}
\hline \hline Station (IAGA code) & Geogr. Coord. & CGM Coord. & MLT NN (UT) \\
\hline Mario Zucchelli Station (TNB) & $74.7 \mathrm{~S} 164.1 \mathrm{E}$ & $80.0 \mathrm{~S} 307.7 \mathrm{E}$ & $20: 11$ \\
Scott Base (SBA) & $77.8 \mathrm{~S} 166.8 \mathrm{E}$ & $80.0 \mathrm{~S} 326.5 \mathrm{E}$ & $19: 01$ \\
Dumont D'Urville (DRV) & $66.7 \mathrm{~S} 140.0 \mathrm{E}$ & $80.4 \mathrm{~S} 235.7 \mathrm{E}$ & $00: 55$ \\
Cambridge Bay (CBB) & $69.2 \mathrm{~N} 255.0 \mathrm{E}$ & $77.2 \mathrm{~N} 309.6 \mathrm{E}$ & $19: 54$ \\
Furstenfeldenbruck (FUR) & $48.2 \mathrm{~N} 11.3 \mathrm{E}$ & $43.4 \mathrm{~N} 86.9 \mathrm{E}$ & $10: 28$ \\
Castello Tesino (CTS) & $46.0 \mathrm{~N} 11.7 \mathrm{E}$ & $40.8 \mathrm{~N} 86.7 \mathrm{E}$ & $10: 28$ \\
L'Aquila (AQU) & $42.4 \mathrm{~N} 13.3 \mathrm{E}$ & $36.3 \mathrm{~N} 87.4 \mathrm{E}$ & $10: 24$ \\
Gibilmanna (GIB) & $37.9 \mathrm{~N} 14.0 \mathrm{E}$ & $30.6 \mathrm{~N} 87.3 \mathrm{E}$ & $10: 24$ \\
\hline
\end{tabular}



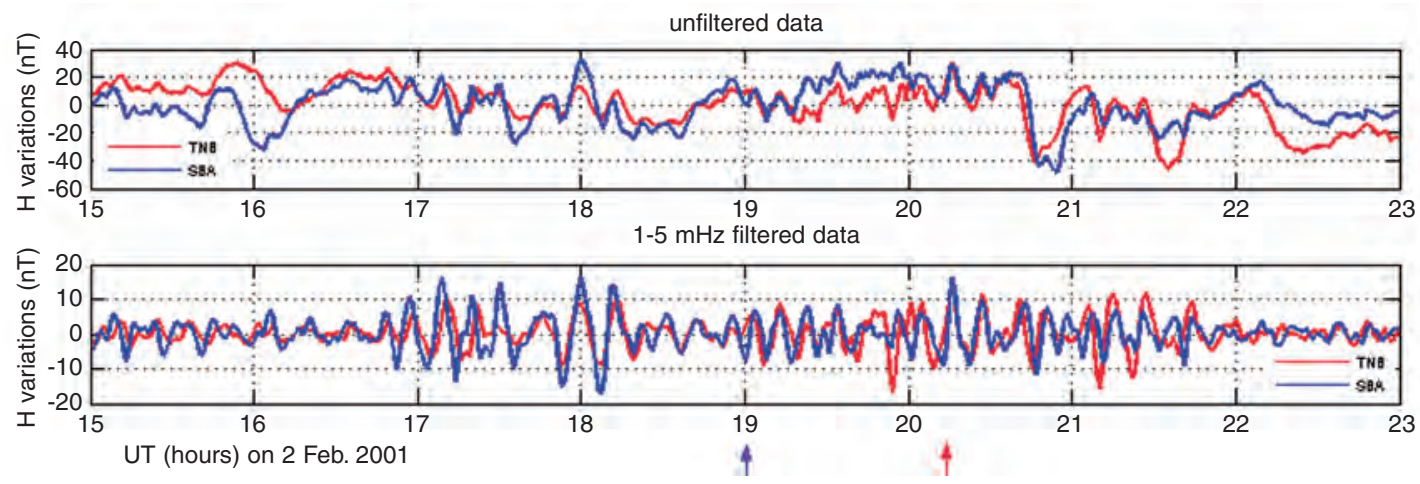

Fig. 7. Variation of the $\mathrm{H}$ component (unfiltered data, upper plot; $1-5 \mathrm{mHz}$ filtered data, lower plot) at TNB (red line) and SBA (blue line). The red and blue arrows indicate the local geomagnetic noon at the two stations, respectively.

open field lines stretching in the geomagnetic tail (Villante et al. 1997; 1998; Lepidi et al., 1999; 2007).

Figure 8 (from Lepidi et al., 2007) shows a pulsation event simultaneously detected at the three Antarctic stations TNB, SBA and Dumont D'Urville (DRV), at the Canadian auroral station Cambridge Bay (CBB) and at a latitudinal chain of European low latitude stations (table I). This event occured on October 30, 2003, during a strong geomagnetic storm triggered by complex interplanetary structures impacting the Earth. The unfiltered data for the time interval 1830-2130 UT (upper panel) show an intense geomagnetic activity, with similar variations at the three Antarctic stations and at the four low latitude stations (in the latter case with a smaller amplitude, so they are less evident in this plot with a common scale for all stations). From the corresponding filtered data (lower left panels; the vertical scale in this case is different for high and low latitude stations, to make more evident the low latitude pulsations) the presence of simultaneous wave packets at all the stations emerges, with an evident signal intensification just before $20 \mathrm{UT}$. The power spectra computed by means of maximum entropy method, at order 20 of the prediction error filter, over the 1930-2130 UT time interval (right panels) show the presence of discrete frequencies, the same at all the stations (around 3.2 and $4.2 \mathrm{mHz}$ ). The same oscillations are present both on field lines closed in the inner magnetosphere (low latitude European stations) and on open field lines stretching in the magnetic tail (high latitude stations), so they can be interpreted in terms of global magnetospheric oscillation modes (Lepidi et al, 2007). In general, the study of such global oscillations of the magnetospheric cavity/waveguide is particularly interesting in that it can give information on the magnetospheric structure, in particular gradients and density profiles.

\section{Summary and conclusions}

The continuous and global monitoring of the Earth's magnetic field is the only means to study the different features of the field and especially of its time variations. This activity is regularly undertaken by geomagnetic observatories all over the world. As is well known, the global distribution of geomagnetic observatories is strongly unbalanced in favor of the northern hemisphere, with a poor coverage in the southern hemisphere. In spite of this, geomagnetic field measurements in polar regions are very important for investigating the geomagnetic field structure and its time variations. The polar observatories role is indispensable in contributing to magnetic field models such as IGRF, secular variation investigations, ionospheric and magnetospheric dynamics. 

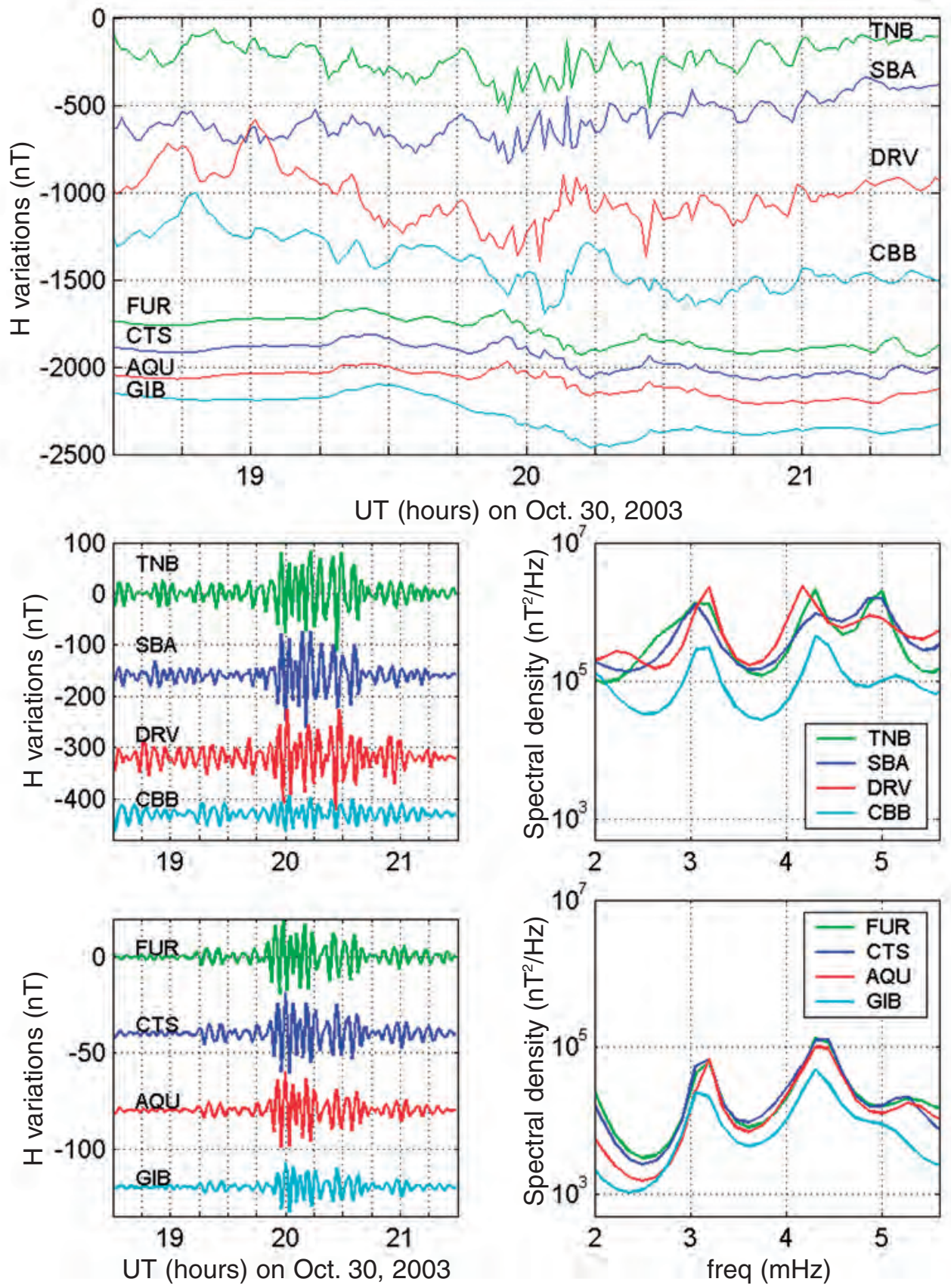

Fig. 8. Variations of the $\mathrm{H}$ component (unfiltered data, upper plot; $2-5 \mathrm{mHz}$ filtered data, lower left plots) at four high latitude and four low latitude stations (table I) and corresponding power spectra from differenced data (plots on the right). 
In this framework, the importance of magnetic observatories in Antarctica is evident, since they provide the opportunity of continuously monitoring the geomagnetic field in an area where time variations show very peculiar features that can be used to address very general problems.

This paper has described some results obtained from TNB geomagnetic observatory data, for both internal and external Earth studies. The dataset is particularly interesting in that it spans over two decades, providing the opportunity to characterize the phenomena which happen in this very peculiar area. Long-term observations are indeed necessary for the study of geomagnetic field variations both of internal origin, with time scales greater than one year, and of external origin, which have long-term modulations due to seasonal and solar cycle dependence. We have shown how the long term time variation, based upon absolute measurements of the field, is used for secular variation studies and how this phenomenon is quite high in amplitude in Antarctica. The monitoring of the daily variation adds to knowledge of the ionospheric electric currents pattern and reveals its role in modulating the amplitude of magnetic field elements following the solar magnetic activity, in this case for the two solar cycles 22 and 23.

Geomagnetic field rapid time oscillations, commonly called pulsations or micropulsations, are another phenomenon that takes great advantage from polar latitude and especially southern latitude measurements. We have to show here how the comparison between polar latitude stations and also with mid latitudes has led to the identification of possible global oscillation magnetospheric modes.

A desirable observatory distribution all over the word would be a uniform coverage. This is of course very difficult in Antarctica but certainly the efforts are worthwhile and contributions to all classical fields of investigations in geomagnetism, as shown here, are strategic.

\section{REFERENCES}

Alexandrescu, M., D. Gibert, G. Hulot, J.L. Le MouËL and G. SARACCO (1996): Worldwide wavelet analysis of geomagnetic jerks, J. Geophys. Res., 101, 21975-21994.
Akasofu, S.I., B.H. AHN and G.J. Romick (1983): A study of the polar current system using the IMS meridian chains of magnetometers, Space Sci. Rev., 36, 337-413.

Atkinson, G. and T. Watanabe (1966): Surface waves in the magnetospheric boundary as a possible origin of long period geomagnetic micropulsations, Earth Planet. Sci. Lett. 1, 89-91.

Backus, G., R. Parker and C. Constable (1996): Foundations of Geomagnetism (Cambridge University Press).

Bloxham, J., S. Zatman and M. Dumberry (2002): The origin of geomagnetic jerks, Nature, 420, 65-68.

BReKKe, A. (1997): Physics of the upper polar atmosphere (John Wiley \& Sons Ltd in association with Praxis Publishing Ltd), pp. 491.

Cafarella, L., A. Meloni and P. Palangio (1998): Solar cycle 22 control on daily geomagnetic variation at Terra Nova Bay (Antarctica), Annali di Geofisica, 41, 805-811.

Cafarella, L., D. Di Mauro, S. Lepidi, A. Meloni, M. Pietrolungo, L. SANTARelli and J.J. Schott (2007a): Daily variation at Concordia station (Antarctica) and its dependence on IMF conditions, Annales Geophysicae, 25, 2045-2051.

Cafarella, L., M. De Lauretis, D. Di Mauro, P. Francia, S. Lepidi, A. Meloni, P. Palangio, A. Piancatelli, L. SANTARELli, M. Vellante and U. Villante (2007b): ULF geomagnetic pulsations at high latitudes: the Italian contribution, (Publs. Inst. Geophys. Pol. Acad. Sc.), C-99, 398, 360-365.

Chapman, S. and J. Bartels (1940): Geomagnetism (Oxford University Press, Oxford).

Chambodut, A, and M. Mandea (2005): Evidence for geomagnetic jerks in comprehensive models, Earth Planets Space, 57, 139-149.

De Michelis, P., L. Cafarella and A. Meloni (2000): A global analysis of the 1991 geomagnetic jerk, Geophys. J. Int., 143, 545-556.

De SAntis, A., R. TozzI and L. Gaya-PiouÉ (2004): Information Content and K-entropy of the Present Earth Magnetic Field, Earth Planet. Sci. Lett., 218, 269-275.

Engebretson, M.J., C.-I. Meng, R.L. Arnoldy and L.J. CAHILl Jr. (1986): Pc3 pulsations observed near the south polar cusp, J. Geophys. Res., 91, 8909-8918.

Greenstadt, E.W., R.L. McPherron and K. TAKahashi (1981): Solar wind control of daytime, midperiod geomagnetic pulsations, in ULF pulsations in the magnetosphere, (Tokyo, Center for Academic Publications Japan, Dordrecht, D. Reidel Publishing Co.), pp. 89-110.

Gubbins, D., A.L. Jones and C.C. Finlay (2006): Fall in Earth's magnetic field is erratic, Science, 312, 900-902.

HARgREAVES, K.J. (1992): The Solar-Terrestrial Environment, (Cambridge University Press).

Kivelson, M.G. and C.T. Russell (1996): Introduction to Space Physics, (Cambridge University Press).

Kivelson, M. and D. Southwood (1985): Resonant ULF waves: a new interpretation, Geophys. Res. Lett., 12, 49-52.

LANZA, R. and A. Meloni (2006): The Earth's magnetism, an introduction for geologist, (Springer).

Lepidi, S., U. Villante, M. Vellante, P. Palangio and A. MelONI (1996): High resolution geomagnetic field observations at Terra Nova Bay, Antarctica, Annali di Geofisica, 34, 519-528.

Lepidi, S., P. Francia, U. Villante, A. Meloni, A.J. 
LAZARUS and R.P. LEPPING (1999): The Earth's passage of the April 11, 1997 coronal ejecta: geomagnetic field fluctuations at high and low latitude during northward interplanetary magnetic field conditions, Ann. Geophysicae, 17, 1245-1250.

Lepidi, S., L. Cafarella, P. Francia, A. Meloni, P. PalanGIO and J.J. SснотT (2003): Low frequency geomagnetic field variation at DomeC (Antarctica), Annales Geophysicae, 21, 923-932.

Lepidi, S., L. Cafarella and L. Santarelli (2007): Low Frequency Geomagnetic Field Fluctuations at cap and low latitude During October 29-31, 2003, Annals of Geophysics, 50, 249-257.

LlOYD, H. (1861): On earth-currents, and their connexion with the diurnal changes of the horizontal magnetic needle, Trans. Roy. Irish Acad., 24, 115-141.

MandeA, M. and M. PurucKer (2005): Observing, modeling and interpretating magnetic fields of the solid Earth, Survey in geophysics, 26, 415-459.

Matsushita, S. and W. Xu (1982): Equivalent ionospheric current system representing solar daily variations of the polar geomagnetic field, J. Geophys. Res, 87, 8241-8254.

MCPHERRON, R. (2008): Response of the Earth's magnetosphere to changes in the solar wind, Journal of Atmospheric and Solar-Terrestrial Physics, 70 (2-4), 303-315.

Meloni, A., P. Palangio, L. Cafarella, G. Romeo, E. Bozzo and G. Caneva (1994): The Geomagnetic observatory at Terra Nova Bay Base, in Terra Antartica, vol. 1, pp. 181-183.

Meloni, A., L. Gaya-Piquet, P. De Michelis and A. De SANTIS (2006): Some recent characteristics of geomagnetic secular variation in Antarctica, rom, in Antarctica: Contributions to global earth sciences, edited by FÜTTERER D.K. et al., (Spring-Verlag, Berlin Heidelberg New York), pp. 377-382.

Meloni, A., L. Cafarella, P. De Michelis, A. De Santis, D. Di Mauro, G. Dominici, S. Lepidi, P. Palangio, R. TozZI and A. ZiRIZZOTTI (2007a): Systematic Magnetic Observations in Italy, (Publs. Inst. Geophys. Pol. Acad. Sc.), C-99 (398), pp. 209-216.

Meloni, A., L. Cafarella, P. De Michelis and R. Tozzi (2007b): The contribution of geomagnetic observatories and Magnetic Models to the study of secular variation and jerks in Antarctica, Geological Survey and The National Academies, (USGS OF-2007-1047, Short Research Paper 071), doi:10.3133/of2007-1047.srp071.
Merril, R.T., M.W. McElhinny P.L. and McFadden (1996): The magnetic field of the Earth: Paleomagnetism, the Core and the Deep Mantle (Academic Press, San Diego, California).

Palangio, P., A. Meloni, L. Cafarella and A. Zirizzotti (1996): Magnetic field measurements at Terra Nova Bay geomagnetic observatory, in Italian Geophysical Observatories in Antarctica, edited by A. MELONI and A. MorelLi, pp. 21-36.

PARKInSON, W.D. (1983), Introduction to Geomagnetism (Scottish Academic Press, Edimburgh).

Rajaram, G., T. Arun, A. Dhar and G. Patil (2002): Rapid decrease in total magnetic field $\mathrm{F}$ at Antarctic stations - its relationship to core-mantle features, Antarctic Science, 14, 61-68.

Santarelli, L., L. Cafarella, S. Lepidi, D. Di Mauro, A. Meloni and P. Palangio (2007a): Fourteen years of geomagnetic daily variation at Mario Zucchelli Station (Antarctica), Annals of Geophysics, 50, 225-232.

Santarelli, L., S. LePidi and L. CAFArella (2007b): Propagation of low frequency geomagnetic field fluctuations in Antarctica: comparison between two polar cap stations, Ann. Geophysicae, 25, 2405.

Schott, J.J., D. Di Mauro, A. Peres, L. Cafarella, L. Magno, A. Zirizzotti and A. Meloni (2005): Towards the opening of a magnetic observatory at Dome C (Antarctica), Proceedings of XIth IAGA Workshop on geomagnetic observatory instruments, data acquisition and processing, Nov 9-17 2004.

Villante, U., S. Lepidi, P. Francia, A. Meloni and P. PALANGIO (1997): Long period geomagnetic field fluctuations at Terra Nova Bay (Antarctica), Geophys. Res. Lett., 24, 1443-1446.

Villante, U., P. Francia, S. Lepidi, M. De Lauretis, E. Pietropalo, L. Cafarella, A. Meloni, A.J. LAZARUs, R.P. LePPING and F. MARIANi (1998): Geomagnetic field variations at low and high latitude during the January 10-11, 1997 magnetic cloud, Geophys. Res. Lett., 25, 2593-2596.

Villante, U., S. Lepidi, P. Francia, M. Vellante, A. Meloni and P. PAlangio (2000): ULF fluctuations at Terra Nova Bay (Antarctica), Annali di Geofisica, 43, 217-227.

Zhou, X.-W., C.T. Russell, G. Le, S.A. Fuselier and J.D. SCUDDER (2000): Solar wind control of the polar cusp at high altitude, J. Geophys. Res., 105, 245-251. 